\title{
Relationship between pressure and thermal pain threshold, pain intensity, catastrophizing, disability, and skin temperature over myofascial trigger point in individuals with neck pain
}

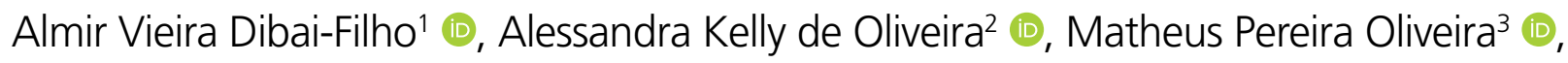 \\ Débora Bevilaqua-Grossi ${ }^{2,3}$ (ㄹ), Rinaldo Roberto de Jesus Guirro ${ }^{2,3 *}$ (1)
}

\section{SUMMARY}

OBJECTIVE: The objective of the study was to correlate the thermal pain threshold (heat and cold) on myofascial trigger points with measurements of pain and skin temperature in patients with chronic neck pain.

METHODS: This is a cross-sectional study. We included participants of both genders, aged between 18-45 years, with chronic neck pain (>90 days), and with active bilateral myofascial trigger point centrally located in the upper trapezius muscle. Neck Disability Index, Numerical Rating Scale, Pain-Related Catastrophizing Thoughts Scale, algometry, infrared thermography, and quantitative sensory testing were used for the evaluation.

RESULTS: A significant, weak, and negative association was observed between pain intensity and heat pain threshold on the myofascial trigger point to the right (rho $-0.381, \mathrm{p}=0.022$ ) and to the left (rho $-0.334, \mathrm{p}=0.049$ ), and a significant, weak, and positive association was observed between pain intensity and cold pain threshold on the myofascial trigger point to the right ( $r$ ho $0.471, p=0.004$ ) and to the left ( $r$ ho $0.339, p=0.043$ ). CONCLUSION: Thermal pain threshold (heat and cold) on myofascial trigger points is associated with pain intensity in individuals with chronic neck pain.

KEYWORDS: Physical therapy. Myofascial pain syndrome. Muscle.

\section{INTRODUCTION}

Myofascial trigger points are dysfunctional structures present in several primarily musculoskeletal diseases, such as neck pain $^{1}$. Considering the multidimensional characteristic of pain, the assessment of a patient with myofascial trigger points also involves the measurement of aspects related to peripheral and central sensitization ${ }^{2}$. The quantitative sensory testing (QST) measures the somatosensory function and can be used as an instrument to investigate inadequate function (hypoalgesia) as well as gain of function (hyperalgesia). In addition, QST

\footnotetext{
1 Universidade Federal do Maranhão, Postgraduate Program in Physical Education - São Luís (MA), Brazil.

2Universidade de São Paulo, Ribeirão Preto Medical School, Department of Health Sciences, Postgraduate Program in Rehabilitation and Functional Performance - Ribeirão Preto (SP), Brazil.

${ }^{3}$ Universidade de São Paulo, Ribeirão Preto Medical School, Department of Health Sciences, Physical Therapy Course - Ribeirão Preto (SP), Brazil. *Corresponding author: rguirro@fmrp.usp.br

Conflicts of interest: the authors declare there is no conflicts of interest. Funding: São Paulo Research Foundation (FAPESP, grants 2013/19368-8 and 2013/09753-1), Coordination for the Improvement of Higher Education Personnel (CAPES, Finance Code 001), and National Council for Scientific and Technological Development (PIBIC-CNPq).
}

Received on September 14, 2021. Accepted on September 16, 2021. 
allows the assessment of allodynia, an important marker of central sensitization ${ }^{3-5}$.

The scientific literature is scarce in terms of studies that investigated the thermal pain threshold on myofascial trigger points. This clinical measure is important to identify the functioning of peripheral reception and interpretation of hot and cold stimuli ${ }^{6,7}$. Thus, describing these aspects is important to understand the clinical complexity involved in chronic painful disorders associated with the presence of myofascial trigger points.

Given the above, this study aimed to correlate the thermal pain threshold (heat and cold) on myofascial trigger points with measurements of pain and skin temperature in patients with chronic neck pain.

\section{METHODS}

\section{Ethical aspects}

The research procedures were approved by the Research Ethics Committee of the institution, opinion number 030643/2013. The recruitment of volunteers took place in communities in the city of Ribeiráo Preto (SP, Brazil). The invitation to participate was through verbal communication, posters, radio, and the Internet.

\section{Study design}

This is a cross-sectional study, in which a physiotherapist was responsible for the recruitment, diagnosis of neck pain and myofascial trigger points, assessment of pain and skin temperature, a second professional was responsible for the assessment of the thermal pain threshold, while a third physiotherapist processed and analyzed the collected data.

\section{Sample}

The processing of the sample calculation was performed using the software Ene, version 3.0 (Universitat Autònoma de Barcelona, Barcelona, Spain). The sample size was calculated based on a previous study ${ }^{8}$. The calculation was based on the detection of moderate association ( $\mathrm{r} 0.50)$ between the variables. Thus, considering a statistical power of $90 \%$ and alpha of 0.05 , a total of 34 volunteers were estimated.

Inclusion criteria were as follows: participants of both genders, aged between 18 and 45 years, and with chronic neck pain ( $>90$ days), which was identified according to the following criteria: Neck Disability Index (NDI) score $\geq 5$ points and Numerical Rating Scale (NRS) score $\geq 3$ at rest or during active cervical movement.

In addition, the volunteers presented an active bilateral myofascial trigger point centrally located in the upper trapezius muscle, diagnosed according to the criteria established by the previous studies ${ }^{9}, 10$. It is noteworthy that these diagnostic criteria for myofascial trigger points have acceptable levels of reliability, according to Gerwin et al. ${ }^{9}$, with kappa values ranging between $0.36-0.88$.

Exclusion criteria were as follows: participants who had a history of cervical trauma; head, face, or cervical surgery; cervical hernia; spinal degenerative diseases; having undergone physical therapy treatment in the past three months; use of analgesics, anti-inflammatory drugs, or muscle relaxants in the previous week; the presence of systemic diseases; medical diagnosis of fibromyalgia; and body mass index (BMI) greater than $28 \mathrm{~kg} / \mathrm{m}^{2}$.

\section{Neck disability index}

This is an instrument adapted and validated for the Brazilian population ${ }^{11}$, consisting of 10 questions that investigate neck disability and pain. For each question, it is possible to indicate one in six answers, corresponding to scores $0-5$. Therefore, the total score ranges from $0-50$ points. The higher the score, the greater the disability.

\section{Numerical rating scale}

A simple and easy-to-measure scale consisting of a sequence of numbers, from 0 to 10 , in which the value 0 represents "no pain" and 10 represents "worst imaginable pain." Thus, volunteers graded their neck pain based on these parameters ${ }^{12}$. Pain intensity was assessed with the individual at rest and after active movements of the cervical spine.

\section{Pain-related catastrophizing thoughts scale}

This scale was adapted and validated for the Brazilian population by Sardá Junior et al. ${ }^{13}$ to assess pain catastrophizing. The scale is composed of nine items scaled on a Likert scale ranging from $0-5$ points associated with the words "almost never" and "almost always." The total score is given by the sum of the items, divided by the number of items answered, with the minimum score being 0 and the maximum 5 . There are no cutoff points, with higher scores indicating the greater presence of catastrophic thoughts.

\section{Algometry}

An algometer (Instrutherm, model PTR-300, São Paulo, SP, Brazil) was used to measure the pressure pain threshold (PPT). A previously trained examiner positioned the algometer with a rubber disk measuring $1 \mathrm{~cm}^{2}$ at the end and exerted gradual compression exactly over the myofascial trigger points with a constant velocity of approximately $0.5 \mathrm{~kg} / \mathrm{cm}^{2} / \mathrm{s}$, controlled by the sound feedback of a digital metronome ${ }^{14}$. This measurement 
was performed bilaterally. These points were pressed until the intensity in which the volunteer reported pain. PPT measurement was performed three times for each muscle and the mean value was considered. This assessment has an inter-rater intraclass correlation coefficient (ICC) value of $0.91^{15}$.

\section{Infrared thermography}

To perform this examination, the volunteers remained for $15 \mathrm{~min}$ in an environment at a controlled temperature around $22^{\circ} \mathrm{C}$. A T300 thermal camera model (FLIR Systems, Wilsonville, OR, USA) with an accuracy of up to $0.05^{\circ} \mathrm{C}$ was used. We used an emissivity of 0.98 . Three infrared images were captured in sequence, at a distance of $100 \mathrm{~cm}$ from the volunteer, to allow the framing of the muscles to be evaluated ${ }^{16}$.

To determine the temperature value over the myofascial trigger point, the QuickReport software, version 1.2 (FLIR Systems) was used. Skin temperature measurements were based on previous studies, which identified excellent intra- and inter-examiner reliability for punctual analysis of the infrared image on the myofascial trigger point, with ICC values of 0.95 and 0.90 , respectively ${ }^{17}$. According to a study by Magalháes et al. ${ }^{18}$, the compressive force used to diagnose myofascial trigger points does not affect skin temperature, as long as the procedure is performed $15 \mathrm{~min}$ after the application of force.

\section{Quantitative sensory testing}

The evaluation of the thermal pain threshold was performed through the QST, using the TSA II Neurosensory Analyzer model equipment (Medoc, Ramat Yishai, Israel) for this purpose. To this end, with the volunteer seated in an air-conditioned environment, the examiner positioned the equipment electrode, bilaterally, on the central myofascial trigger point of the upper trapezius muscle. Three repetitions of the test were performed for the heat stimuli, at an initial temperature of $32^{\circ} \mathrm{C}$ and a maximum of $50^{\circ} \mathrm{C}$, and three repetitions were performed for the cold stimuli, at an initial temperature of $32^{\circ} \mathrm{C}$ and a minimum of $0^{\circ} \mathrm{C}$. The participant was instructed to interrupt the temperature change by pressing a sensor whenever it reached an intensity that caused pain, and this value was recorded. For statistical analysis, the mean of the three repetitions was used.

\section{Statistical analysis}

Initially, data distribution was verified using the Shapiro-Wilk test. Therefore, using this observation, the Pearson's correlation coefficient ( $r$ ) was applied to the correlations between variables with normal distribution and Spearman's (rho) to verify the association between variables with non-normal distribution. To interpret the magnitude of the correlations, a previous classification established $^{8}$ was used: weak, from $0.26-0.49$; moderate, from
$0.50-0.69$; high, from $0.70-0.89$; and very high, from 0.90 1.00. Data processing was performed using the Statistical Package for Social Sciences software, version 17.0 (Chicago, IL, USA).

\section{RESULTS}

A total of 53 volunteers of both genders were recruited for the study and 17 volunteers were excluded for the following reasons: five had an NDI score lower than 5 points; four had pain intensity lower than 3 points according to the NRS; four individuals had latent trigger points; three had unilateral trigger point; and one had no trigger points in the upper trapezius muscle.

Thus, 36 volunteers were included in the study: 33 women, 31 right-handers, mean age of 23.68 years (standard deviation [SD] 4.01), mean BMI of 22.42 (SD 2.93), chronicity mean neck pain 50.91 months (SD 37.87), and mean Beck Depression Inventory score of 5.19 points (SD 2.64). In addition, the values of central tendency and dispersion of the study variables are described in Table 1.

Regarding the correlations between the variables, a significant, weak, and negative association was observed between pain intensity and thermal pain threshold (heat) on myofascial trigger point to the right (rho -0.381, $\mathrm{p}=0.022$ ) and to the left (rho -0.334, $\mathrm{p}=0.049$ ), and a significant, weak, and positive association between pain intensity and thermal pain threshold (cold) on myofascial trigger point to the right (rho $0.471, \mathrm{p}=0.004$ ) and to the left (rho $0.339, \mathrm{p}=0.043$ ) was found. Other details are described in Table 2.

\section{DISCUSSION}

Our findings showed that the thermal pain threshold on myofascial trigger points correlates only with pain intensity in chronic neck pain patients. We did not observe a significant correlation with disability, catastrophizing, PPT, and skin temperature. Several studies were carried out with QST and painful disorders. However, our study is the pioneer in investigating the thermal pain threshold in patients with myofascial trigger points.

Considering QST, a systematic review conducted with people with spinal pain identified magnitudes of correlation with pain intensity lower than in the present study (cold pain threshold -0.07 , heat pain threshold -0.07), with no clinical importance. Likewise, the authors identified a negligible magnitude of correlation with disability (cold pain threshold -0.22 , heat pain threshold -0.02). Thus, the authors concluded that the pain threshold is a poor marker of central sensitization or that sensitization does not play a major role in patients' reporting of pain and disability ${ }^{19}$.

Another systematic review carried out with people with musculoskeletal pain noted a weak magnitude of correlation with pain (cold pain threshold 0.14 , heat pain threshold -0.14$)^{20}$. A study points out inconsistent results regarding 
Table 1. Description of mean values, standard deviation, median, first and third quartile of the study variables.

\begin{tabular}{l|c|c|c|c|c} 
& Mean & SD & Median & 1st quartile & 3rd quartile \\
\hline NRS at rest (score) & 3.11 & 1.75 & 3.00 & 2.00 & 4.00 \\
\hline NRS after movements (score) & 5.36 & 1.79 & 5.50 & 4.00 & 7.00 \\
\hline NDI (score) & 11.27 & 4.15 & 11.00 & 8.00 & 14.00 \\
\hline PCTS (score) & 1.29 & 0.92 & 1.16 & 0.55 & 1.88 \\
\hline Right PPT $\left(\mathrm{kg} / \mathrm{cm}^{2}\right)$ & 1.64 & 0.42 & 1.61 & 1.35 & 1.91 \\
\hline Left PPT $\left(\mathrm{kg} / \mathrm{cm}^{2}\right)$ & 1.55 & 0.38 & 1.46 & 1.31 & 1.83 \\
\hline Right ST $\left({ }^{\circ} \mathrm{C}\right)$ & 33.24 & 1.13 & 33.26 & 32.31 & 34.11 \\
\hline Left ST $\left({ }^{\circ} \mathrm{C}\right)$ & 33.20 & 1.20 & 33.43 & 32.23 & 34.01 \\
\hline Right TPT heat $\left({ }^{\circ} \mathrm{C}\right)$ & 42.42 & 3.74 & 43.11 & 39.41 & 45.03 \\
\hline Right TPT cold $\left({ }^{\circ} \mathrm{C}\right)$ & 19.73 & 10.40 & 24.43 & 9.09 & 28.34 \\
\hline Left TPT heat $\left({ }^{\circ} \mathrm{C}\right)$ & 42.22 & 3.69 & 41.80 & 38.95 & 45.26 \\
\hline Left TPT cold $\left({ }^{\circ} \mathrm{C}\right)$ & 19.57 & 9.97 & 23.40 & 13.69 & 28.09 \\
\hline
\end{tabular}

SD: standard deviation; NRS: numerical rating scale; NDI: neck disability index; PCTS: pain-related catastrophizing thoughts scale; PPT: pressure pain threshold; ST: skin temperature; TPT: thermal pain threshold.

Table 2. Correlation between thermal pain threshold and variables related to pain and skin temperature.

\begin{tabular}{l|c|c|c|c} 
NRS at rest (score) & Right TPT heat $\left({ }^{\circ} \mathrm{C}\right)$ & Right TPT cold $\left({ }^{\circ} \mathrm{C}\right)$ & Left TPT heat $\left({ }^{\circ} \mathrm{C}\right)$ & Left TPT cold $\left({ }^{\circ} \mathrm{C}\right)$ \\
\hline $\begin{array}{l}\text { NRS after } \\
\text { movements (score) }\end{array}$ & rho $=-0.121, p=0.483$ & $r h o=0.298, p=0.077$ & $r h o=0.043, p=0.802$ & $r h o=0.203, p=0.235$ \\
\hline NDI (score) & $r h o=-0.003, p=0.988$ & $r h o=0.071, p=0.680$ & $r h o=0.036, p=0.834$ & $r h o=0.017, p=0.921$ \\
\hline PCTS $($ score) & $r=-0.079, p=0.647$ & $r h o=0.291, p=0.085$ & $r=0.025, p=0.886$ & $r h o=0.191, p=0.265$ \\
\hline Right PPT $\left(\mathrm{kg} / \mathrm{cm}^{2}\right)$ & $r=0.105, p=0.541$ & $r h o=0.010, p=0.954$ & $r=-0.034, p=0.845$ & $r h o=0.119, p=0.448$ \\
\hline Left PPT $\left(\mathrm{kg} / \mathrm{cm}^{2}\right)$ & $r=0.091, p=0.600$ & $r h o=0.033, p=0.805$ & $r=-0.088, p=0.609$ & $r h o=0.178, p=0.298$ \\
\hline Right ST $\left({ }^{\circ} \mathrm{C}\right)$ & $r=-0.009, p=0.957$ & $r h o=0.268, p=0.114$ & $r=0.136, p=0.431$ & $r h o=0.116, p=0.499$ \\
\hline Left ST $\left({ }^{\circ} \mathrm{C}\right)$ & $r=0.038, p=0.827$ & $r h o=0.218, p=0.201$ & $r=0.228, p=0.181$ & $r h o=0.093, p=0.589$ \\
\hline
\end{tabular}

TPT: thermal pain threshold; SD: standard deviation; NRS: numerical rating scale; NDI: neck disability index; PCTS: pain-related catastrophizing thoughts scale; PPT: pressure pain threshold; ST: skin temperature; r: Pearson's correlation coefficient; rho: Spearman's correlation coefficient. *Statistically significant correlation.

the behavior of the thermal pain threshold in patients with migraine $^{21}$. In patients with fibromyalgia, a recent systematic review describes a reduction in cold pain thresholds when compared to a control group ${ }^{22}$. In breast cancer survivors, local disturbance in thermal detection and increased pain facilitation were found in these patients with pain in the surgical area $^{23}$.

Other clinical features have already been evaluated in muscles with myofascial trigger points. An important study highlights that the tensiomyography contractile properties did not seem to show differences, while the sonoelastography and mechanosensitivity presented higher stiffness and lower PPT when compared with the control group ${ }^{24}$.
Our study has limitations that must be considered. The sample consisted mostly of women. Thus, future studies can investigate the relationship between thermal pain threshold and gender, with greater inclusion of men. In addition, the sample consisted mostly of young people with a less mean age who were involved in most clinical studies on chronic neck pain.

\section{CONCLUSIONS}

Thermal pain threshold (heat and cold) on myofascial trigger points is associated with pain intensity in individuals with chronic neck pain. 


\section{AUTHORS' CONTRIBUTIONS}

AVDF: Conceptualization, Data curation, Formal Analysis, Methodology, Project administration, Writing - review \& editing. AKO: Conceptualization, Data curation, Formal Analysis, Methodology, Writing - original draft. MPO: Conceptualization,
Data curation, Formal Analysis, Methodology, Writing - original draft. DBG: Conceptualization, Methodology, Writing review \& editing. RRJG: Conceptualization, Data curation, Formal Analysis, Methodology, Project administration, Writing - review \& editing.

\section{REFERENCES}

1. Girasol CE, Dibai-Filho AV, Oliveira AK, Jesus Guirro RR. Correlation between skin temperature over myofascial trigger points in the upper trapezius muscle and range of motion, electromyographic activity, and pain in chronic neck pain patients. J Manipulative Physiol Ther. 2018;41(4):350-7. https://doi.org/10.1016/j.jmpt.2017.10.009

2. Fernández-De-Las-Peñas C, Dommerholt J. Myofascial trigger points: peripheral or central phenomenon? Curr Rheumatol Rep. 2014;16(1):395. https://doi.org/10.1007/s11926-0130395-2

3. Starkweather AR, Heineman A, Storey S, Rubia G, Lyon DE, Greenspan J, et al. Methods to measure peripheral and central sensitization using quantitative sensory testing: a focus on individuals with low back pain. Appl Nurs Res. 2016;29:23741. https://doi.org/10.1016/j.apnr.2015.03.013

4. Rolke R, Magerl W, Campbell KA, Schalber C, Caspari S, Birklein F, et al. Quantitative sensory testing: a comprehensive protocol for clinical trials. Eur J Pain. 2006;10(1):77-88. https:// doi.org/10.1016/j.ejpain.2005.02.003

5. Hansson P, Backonja M, Bouhassira D. Usefulness and limitations of quantitative sensory testing: clinical and research application in neuropathic pain states. Pain. 2007;129(3):256-9. https:// doi.org/10.1016/j.pain.2007.03.030

6. Averbeck B, Seitz L, Kolb FP, Kutz DF. Sex differences in thermal detection and thermal pain threshold and the thermal grill illusion: a psychophysical study in young volunteers. Biol Sex Differ. 2017;8(1):29. https://doi.org/10.1186/s13293017-0147-5

7. Riel $H$, Plinsinga $M L$, Mellor R, Boudreau SA, Vuvan $V$, Vicenzino B. Local hyperalgesia, normal endogenous modulation with pain report beyond its origin: a pilot study prompting further exploration into plantar fasciopathy. Scand J Pain. 2020;20(2):375-85. https://doi.org/10.1515/ sjpain-2019-0109

8. Kellar SP, Kelvin E. Munro's statistical methods for health care research. 6th ed. Philadelphia: Lippincott Williams \& Wilkins; 2012

9. Gerwin RD, Shannon S, Hong CZ, Hubbard D, Gevirtz R. Interrater reliability in myofascial trigger point examination. Pain. 1997;69(1-2):65-73. https://doi.org/10.1016/s03043959(96)03248-4

10. Simons DG, Simons LS, Travell JG. Travell \& Simons' myofascial pain and dysfunction: the trigger point manual. 2nd ed. Philadelphia: Lippincott Williams \& Wilkins; 2020

11. Cook C, Richardson JK, Braga L, Menezes A, Soler $X$, Kume $P$, et al. Cross-cultural adaptation and validation of the Brazilian Portuguese version of the Neck Disability Index and Neck Pain and Disability Scale. Spine (Phila Pa 1976). 2006;31(14):1621-7. https://doi.org/10.1097/01. brs.0000221989.53069.16
12. Ferreira-Valente MA, Pais-Ribeiro JL, Jensen MP. Validity of four pain intensity rating scales. Pain. 2011;152(10):2399404. https://doi.org/10.1016/j.pain.2011.07.005

13. Sardá Junior J, Nicholas MK, Pereira IA, Pimenta CAM, Asghari A, Cruz RM. Validation of the pain-related catastrophizing thoughts scale. Acta Fisiátrica. 2008;15(1):31-6. https://doi. org/10.5935/0104-7795.20080001

14. Dibai-Filho AV, Oliveira AK, Girasol CE, Dias FRC, Guirro RRJ. Additional effect of static ultrasound and diadynamic currents on myofascial trigger points in a manual therapy program for patients with chronic neck pain. Am J Phys Med Rehabil. 2017;96(4):243-52. https://doi.org/10.1097/ PHM.0000000000000595

15. Chesterton LS, Sim J, Wright CC, Foster NE. Interrater reliability of algometry in measuring pressure pain thresholds in healthy humans, using multiple raters. Clin J Pain. 2007;23(9):760-6. https://doi.org/10.1097/AJP.0b013e318154b6ae

16. Costa AC, Dibai Filho AV, Packer AC, Rodrigues-Bigaton D. Intra and inter-rater reliability of infrared image analysis of masticatory and upper trapezius muscles in women with and without temporomandibular disorder. Braz J Phys Ther. 2013;17(1):2431. https://doi.org/10.1590/s1413-35552012005000058

17. Dibai-Filho AV, Guirro EC, Ferreira VT, Brandino HE, Vaz MM, Guirro RR. Reliability of different methodologies of infrared image analysis of myofascial trigger points in the upper trapezius muscle. Braz J Phys Ther. 2015;19(2):122-8. https:// doi.org/10.1590/bjpt-rbf.2014.0076

18. Magalhães MF, Dibai-Filho AV, Oliveira Guirro EC, Girasol CE, Oliveira AK, Dias FR, et al. Evolution of skin temperature after the application of compressive forces on tendon, muscle and myofascial trigger point. PLoS One. 2015;10(6):e0129034. https://doi.org/10.1371/journal.pone.0129034

19. Hübscher M, Moloney N, Leaver A, Rebbeck T, McAuley JH, Refshauge KM. Relationship between quantitative sensory testing and pain or disability in people with spinal pain-a systematic review and meta-analysis. Pain. 2013;154(9):1497504. https://doi.org/10.1016/j.pain.2013.05.031

20. Georgopoulos $V$, Akin-Akinyosoye $K$, Zhang W, McWilliams DF, Hendrick P, Walsh DA. Quantitative sensory testing and predicting outcomes for musculoskeletal pain, disability, and negative affect: a systematic review and meta-analysis. Pain. 2019;160(9):1920-32. https://doi.org/10.1097/j. pain. 0000000000001590

21. Nahman-Averbuch H, Shefi T, Schneider VJ 2nd, Li D, Ding L, King $C D$, et al. Quantitative sensory testing in patients with migraine: a systematic review and meta-analysis. Pain. 2018;159(7):120223. https://doi.org/10.1097/j.pain.0000000000001231

22. Berwick RJ, Siew S, Andersson DA, Marshall A, Goebel A. A systematic review into the influence of temperature on fibromyalgia pain: meteorological studies and quantitative 
sensory testing. J Pain. 2021;22(5):473-86. https://doi. org/10.1016/j.jpain.2020.12.005

23. Dams L, Gucht EV, Meeus M, Devoogdt N, Smeets A, Penen $F$, et al. Quantitative sensory testing in women after surgery for breast cancer: a systematic review and narrative synthesis. Clin J Pain. 2021;37(7):538-64. https://doi.org/10.1097/ AJP.0000000000000940
24. Calvo-Lobo C, Diez-Vega I, Martínez-Pascual B, FernándezMartínez S, Cueva-Reguera M, Garrosa-Martín G, et al. Tensiomyography, sonoelastography, and mechanosensitivity differences between active, latent, and control low back myofascial trigger points: a cross-sectional study. Medicine (Baltimore). 2017;96(10):e6287. https://doi.org/10.1097/ MD.0000000000006287 